\title{
Stage IIB Small Intestinal Adenocarcinoma AJCC v8
}

National Cancer Institute

\section{Source}

National Cancer Institute. Stage IIB Small Intestinal Adenocarcinoma A/CC v8. NCI

Thesaurus. Code C133898.

Stage IIB includes: T4, NO, M0. T4: Tumor perforating the visceral peritoneum or directly invading other organs or structures (e.g., other loops of small intestine, mesentery of adjacent loops of bowel, and abdominal wall by way of serosa; for duodenum only, invasion of pancreas or bile duct). N0: No regional lymph node metastasis. M0: No distant metastasis. (AJCC 8th ed.) 